\title{
InCReasing Student Awareness of Professionalism USING THE PROFESSIONALISM ASSESSMENT TOOL (PAT) IN A SENIOR UNDERGRADUATE ENGINEERING DESIGN COURSE
}

\author{
Samantha Mehltretter and Andrea Bradford \\ School of Engineering, University of Guelph \\ mehltres@uoguelph.ca
}

\begin{abstract}
The Canadian Engineering Accreditation Board's definition of professionalism, one of twelve graduate attributes, does not mention professional behaviour, but rather focuses on understanding the role of engineers in society. While difficult to define, challenging to teach, and even harder to assess, the engineering faculty at the University of Guelph felt professional behaviour was an important element of professionalism to consider in their curriculum.

This study investigates how professional behaviour might be taught and assessed. The researchers developed course material on professional behaviour for the winter 2019 offering of a third-year multidisciplinary design course (369 students), using Kelley et al.'s (2011) Professionalism Assessment Tool (PAT). Using a quasiexperimental design, the researchers assessed whether student professionalism improved based on their change in PAT scores over the semester using a Wilcoxon SignedRank test. They also analyzed a sample of student final reflections on professional behaviour.

Student PAT scores increased significantly over the semester ( $n=340, p<0.05)$, but the effect sizes observed, using Cohen's $d$, were small (0.14 to 0.29). The student reflections $(n=53)$ suggest that improvements to their professionalism were a result of working in a team, experience gained from their project, and individual efforts made to behave professionally. While infrequently discussed in the reflections, over half of the post-term survey responses revealed that students felt the lab activities helped improve their professional skills generally, and/or increased their awareness of these skills. The improved awareness aspect of student professionalism was an unexpected, but important outcome of the PATbased course material and may have reinforced student ownership of their soft skill development.
\end{abstract}

Keywords: Professionalism, Interdisciplinary Design, Student Behaviour, Assessment Tool, Problem-Based Learning.

\section{INTRODUCTION}

The Canadian Engineering Accreditation Board (CEAB) added twelve Graduate Attribute (GAs) to their accreditation processes in response to the Washington Accord in 2014 (Canadian Engineering Accreditation Board, 2015) [1]. While CEAB provides definitions of each GA, it is up to each individual institution (or program) to identify indicators that can be measured to assess student development of the GA. The indicators must encompass the CEAB definition, but they can also expand beyond it. For example, the University of Guelph's School of Engineering Faculty decided to add an indicator of professional behaviour to assess the Professionalism GA. The challenge is professional behaviour is an abstract construct, which makes it difficult to teach and assess.

The purpose of this research is to better understand how to teach and assess professional behaviour. Specifically, in the first year of the study, the researchers focused on using student self-assessments of professional behaviour within a large multidisciplinary engineering design course. The study objectives include the following:

1. Implement and assess a professional behaviour assessment tool for student self-assessment.

2. Determine whether self-assessed student professional behaviour improves in a problembased learning course.

3. Explore student perceptions of professional behaviour and the assessment tool.

\subsection{Professionalism \& Professional Behaviour}

The CEAB defines professionalism as "An understanding of the roles and responsibilities of the professional engineer in society, especially the primary role of protection of the public and the public interest" [1]. This definition emphasizes the cognitive as opposed to behavioural aspects of professionalism. However, applicants for licensure in Canada must "be of good character" [2], [3]. As such, an individual's behaviour is also an important component of becoming an engineer. Teaching and assessing professional behaviour within the 
curriculum prepares students for the expectations of the profession.

Engineers Canada (2010) prepared a national model guide on professionalism, for regulatory bodies and practitioners. This guide, which takes a comprehensive view of professionalism, discusses an engineer's duty to the public, their specialized knowledge, and their personal character [4].

In order to uphold one's duty to the public as an engineer, technical competencies are required, so specialized knowledge is an important element of professionalism [4]. Engineers Canada (2010) specifically indicates that professionals require specialized knowledge, and the ability to apply expert judgement of that knowledge [4]. This includes analyzing risk, discretionary decisionmaking, and upholding a certain quality of work, which are also apparent in other professions [5]. Due to the nature and complexity of specialized knowledge, a profession must be self-regulated and professionals autonomous and accountable for their work [4]-[6]. Furthermore, because of the rapid changes in technology in today's world, engineers are required to engage in continued study in order to maintain expertise and specialized knowledge within their field [4].

The engineering profession is recognized for its specialized knowledge and duty to the public; however, it is founded in the personal character of its engineers. An individual's actions, and thus their character, reflects on the profession as a whole. Unprofessional behaviour from an individual can taint the reputation of the engineering profession and erode the public's trust. Engineers Canada (2013) explains that "Good character connotes moral and ethical strength and includes traits such as integrity, candour, honesty and trustworthiness" [3].

Evetts (2011 \& 2013) investigated the meaning of professionalism through a sociological lens. One interpretation she explores is that professionalism is a value-system formed by the profession. This value-system helps establish trust between the professional and the client [6]. Personal character traits discussed in reference to professionalism are a lack of arrogance and selfsatisfaction, and a presence of autonomy, ethics, and respect for others [4]-[6]. Each of these characteristics hold true for engineers, and as such contribute to the definition of behavioural professionalism.

The more comprehensive definitions of professionalism from Engineers Canada's (2010 \& 2013) and from Evetts (2011 \& 2013) sociological analysis, support the addition of the professional behaviour indicator to more fully assess the Professionalism graduate attribute. However, they also illustrate the complexity of this construct, and whats more demonstrate that conventional lectures are unlikely to be sufficient in fostering professionalism in engineering students.

\subsection{Teaching Professional Skills}

While technical knowledge and skills are explicitly taught and assessed in traditional engineering curricula, students are often expected to figure out on their own how to engage and work productively in a team, how to demonstrate professional behaviour, and how to regulate their learning [7]. Active learning strategies, like problembased learning (PBL), are often used as platforms to support professional skill development. This approach has students work, typically in teams, to solve a problem and learn technical and professional skills through that process [7], [8]. Before students can practice and develop their professional skills in a PBL environment, however, it is important they are given direct instruction on the professional skills. Then they can practice their newly acquired knowledge in a safe classroom environment. Finally, to develop their professional skills, students require feedback through an assessment process [9].

Direct instruction of professional skills often follows a cognitive view of learning where, students engage in mental processes to gain different types of knowledge, including: declarative (knowing what), procedural (knowing how), and conditional (knowing when to use the knowledge) [9]. Behavioural views of learning describe learning as a process in which antecedent conditions shape the behaviour of an individual, and the consequences either strengthen or weaken a tendency toward that behaviour [9]. In contrast, cognitive views of learning suggest that a behaviour and its consequence provides information to the person, which is then used to make decisions regarding future behaviours [9]. Each theory differs in what mechanism fosters learning; however, both theories suggest that learning is influenced by an individual's experience with a behaviour. Therefore, once students are provided with the knowledge (declarative, procedural, and conditional) of professional behaviour, they will need time to practice applying the skills or experiencing the behaviour and its consequences.

While having time and an experiential scenario to practice skills is important, the key component of learning is a consequence. In the context of the classroom and development of professional skills, the consequence to a behaviour is through feedback, or formative assessment [8], [10]. Formative feedback typically does not contribute greatly to the final grade, which allows students to learn through failure (getting it wrong) without significant consequence [8]. Once the student receives feedback, they must then reflect upon it to successfully grow from the learning experience [9], [11]. The reflective step is crucial if the student is to develop their professional skills and deepen the learning from the experience [12], [13]. The assessment and quality of feedback received is therefore important to encourage professional development. 


\subsection{Assessing Professional Behaviour}

Providing students with feedback on their professional behaviour requires some form of assessment. The Professionalism Assessment Tool (PAT) was developed by Kelley et al. (2011) to provide a self-assessment measure of professionalism for doctoral pharmacy students [14]. While there are other professionalism scales used to evaluate pharmacy students, Kelley et al. (2011) found that these scales had a ceiling effect in which students tended to rate themselves at the top of the measure. This limited the applicability of the measure to demonstrate improvement of student professionalism throughout the pharmacy program, and further inhibited its use for informing changes to the curriculum. As a result, Kelley et al. (2011) took two existing professionalism scales, from Hammer et al. (2000) and Chisholm et al. (2006) that focused on behavioural professionalism and used these, along with a white paper on professionalism in pharmacy to inform the development of the new scale [15], [16]. The finalized 33item scale covers 5 domains of professionalism: (1) Reliability, Responsibility, \& Accountability (RRA); (2) Lifelong Learning \& Adaptability (LLA); (3) Relationships with Others (RwO); (4) Upholding Principles of Integrity \& Respect (PIR); and (5) Citizenship $\&$ Professional Engagement (CPE). Each item is evaluated using a modified version of Miller's Taxonomy (Knows, Knows How, Shows, Shows How/Does, and Teaches) [14].

The scale was tested on approximately 1200 pharmacy doctoral candidates in first and third year from 7 different institutions in the United States [14]. An exploratory factor analysis was conducted to identify the factors of the scale on half of the data (randomly selected), and then a confirmatory factor analysis using the same factor structure was applied to the remaining data. The items loaded onto the expected factors and had loadings over 0.5 for only the expected factor. The reliability of each factor using the KR20 statistic was then calculated and ranged from $0.91-0.95$ indicating excellent reproducibility [14]. These tests support the measure's validity.

\subsection{Course Context}

Engineering \& Design III (often referred to as Design III) is a 3 rd year course offered in the 6 th or $7_{\text {th }}$ academic semester for students in the regular and co-op programs, respectively. The course is a requirement for all engineering students and is an opportunity for students from different disciplines to work together to solve a moderately complex open-ended problem. As the course is offered once per year (in the winter semester), the class size is large, around $300-400$ students. Problem-based learning is used to teach students about the design process. This pedagogical strategy is also used to foster professional skill development, including teamwork, lifelong learning and more recently professionalism.
All deliverables and assessments for the course are related to the project, and there is no final exam. Each project deliverable is a team assessment, and students only submit two individual assignments in Design III: an interim reflection midway through the term and a final reflection at the end of the semester. Process grades, which reflect a student's design process during the course are given to students individually. These evaluations, which include assessment of student professional skills, are based primarily on observations made by the instructor and graduate teaching assistant (GTA) throughout the course, along with some consideration of peer evaluations.

The course consists of 3 hours of lecture a week where broader design related concepts are discussed, and a 2-hour lab period where 5 to 6 teams have time to work on their project and interact with a GTA and an instructor. The lab period is often used to give teams feedback on previous deliverables, and answer questions related to upcoming requirements; however, the structure is very informal. These weekly labs are a unique opportunity for students to receive regular targeted feedback from an instructor and GTA. This study was conducted because the teaching team wanted to take advantage of this unique opportunity to support greater professional skill development, including fostering professional behaviour.

\section{METHODOLOGY}

The study was implemented in the winter 2019 offering of Design III, which had a class of 369 students. A mixed methods experimental design was used to identify selfassessed changes in student professional behaviour, along with student perceptions of their professional behaviour and the delivery of the course.

\subsection{Study Design}

The intentional instruction of professionalism was delivered in lectures and lab-activities. During the first lab a professionalism workshop was delivered where students spent two hours brainstorming and reflecting on professional behaviour. The workshop included four activities: (1) brainstorming what professionalism means, initially with no aids and later using the PAT domains to stimulate ideas; (2) discussing scenarios with unprofessional behaviour and/or difficult situations; (3) self-assessing as a group on several professionalism items from the PAT; and, (4) developing a rubric for one of the PAT domains. The results of the workshop were aggregated and presented in lecture the following week. Elements of professional behaviour were also discussed in a Conflict Resolution lecture mid-way through the semester, namely, how to have difficult conversations in a professional manner when conflict arises. This lecture was followed with an in-lab activity where students practiced giving their team members constructive feedback and receiving feedback graciously and respectfully. 
Student professionalism was quantified using Kelley et al.'s (2011) PAT. The PAT was selected for this study based on the strong evidence for validity, its domain structure, and the ease with which it can be adapted to the engineering context. While written for pharmacy doctoral students, many of the items are general and can be easily used by individuals in other professions. Two of the 33 items refer to patient interactions, which is not applicable for engineering students. As a result, both references to patients were replaced with the word stakeholder as the stakeholders on a project would be akin to the patient of a pharmacist or someone in a health care profession. The word stakeholder was selected instead of client or public as the researchers wanted to encompass the need to be professional with all people involved in the project. It emphasizes the need for engineers to consider many different perspectives, rather than just that of the client.

Using a pre-test/post-test quasi-experimental design, students self-assessed their professionalism before and after the course. Before their first lab in Week 1, students were required to complete the pre-term survey, which included Kelley et al.'s (2011) PAT. Students took the post-term survey, which included the PAT and several perception items, during Week 11 (the second last week of class). Both the pre-term and post-term PAT scores were returned to the students during the last week of class (Week 12). Students used their scores to complete a final reflection that focused on their professionalism throughout the course, and asked students to comment on whether they felt their PAT scores were reflective of their experience. A sample of the reflections were used as the qualitative data of the mixed methods study.

\subsection{Quantitative Analysis}

All quantitative data was cleaned prior to use, including removal of survey data from students that did not complete both surveys. In total 340 out of 369 students completed both surveys in winter 2019. Then the PAT domain scores were calculated. A check for normality using ShapiroWilks was conducted on all quantitative data to determine whether parametric or non-parametric tests were more suitable. As most of the data from the surveys were not normally distributed, the researchers compared means using the Wilcoxon-Ranked Sign test $(\alpha<0.05)$. If the difference in means was significant, Cohen's $d$ was calculated to determine the size of the effect. An effect size of 0.2 was considered small, 0.5 was moderate and 0.8 was large [17]. Descriptive statistics and visual representations (e.g. bar charts) were used to analyze the perception items. Any further quantitative analysis is described as the results are presented.

\subsection{Qualitative Analysis}

The final reflections asked students to discuss their professionalism throughout the course and whether they felt their PAT scores were reflective of their experience. Students were asked to discuss two of the five domains of professionalism. The reflections were analyzed using a directed content analysis, in which codes are defined prior to analyzing the reflections [18]. Then, the qualitative research software, NVivo 12, was used to identify ideas in the reflections that reflected the codes. This process is referred to herein as coding. Ideas were used as coding units rather than phrases or words, because the student reflections of their professionalism varied considerably in terms of level of detail included and concision of writing.

The primary analysis included five main codes: Improve, Static, Decline, Awareness, and Factor. The first three codes reference a type of change in professionalism, while Awareness is referring to a student discussing their increased mindfulness of their professionalism rather than a change in it. Finally, Factor was used to categorize anything that influenced the change in professionalism and/or improved awareness of professionalism. A list of these factors (sub-codes) was created from twelve randomly sampled reflections. This is in accordance with Guest, Bunce, and Johnson (2006), who found that theme saturation was reached after reviewing 12 interviews [19]. It is assumed that saturation of themes in interviews would be similar in written reflections.

A secondary directed content analysis was conducted using codes that categorized how reflective (or accurate) students felt their PAT scores were of their experience. The codes included: Reflective when students said their preterm and post-term scores for both professionalism domains were reflective of their experience; Mostly Reflective when more scores were reflective than not; Somewhat Reflective when most scores were deemed not reflective; and Not Reflective when the student felt none of the PAT scores were reflective of their experience.

As there were 369 students in the class, who each wrote a three-part interim and three-part final reflection, it was not feasible to analyze all reflections. As such, a stratified random sampling method was used to get a cross section of responses for the analysis. Using the difference between the pre- and post-term total PAT scores for each student, the participants were ranked from greatest increase to greatest decrease in score. Then reflections were randomly sampled at the $90_{\mathrm{th}}, 50_{\mathrm{th}}$, and $10_{\mathrm{th}}$ percentile scores. This approach ensured that discussions of scores that increased, decreased and stayed approximately the same were included in the sample. In total, 53 unique final reflections were analyzed. Once the coding was completed, the

\footnotetext{
1A larger study analyzed student final reflections for two graduate attributes (GA): professionalism and lifelong learning. The same approach for the stratified random sample was used for the LLA scores for Lifelong Learning as the total PAT scores for professionalism. As such 10 final reflections were selected from each of the $90 \mathrm{th}, 50 \mathrm{th}, \& 10_{\mathrm{th}}$ percentile of the changes in scores for each of the two GAs, totalling 53 unique final reflections (some reflections were selected for both GAs). All 53 reflections were coded for both GA analyses.
} 
researchers analyzed the results by counting the number of reflections with certain codes.

\section{RESULTS AND DISCUSSION}

The winter 2019 offering of Design III included 369 students at the beginning of the semester, coming from seven engineering disciplines. In total, 340 students completed both surveys and both reflections and were retained for the purpose of the study. This leaves a small nonresponse bias of less than $8 \%$. The reflections analyzed only represent $14 \%$ of the class; however, the qualitative analysis provides greater insight into the student's perceived professionalism during Design III, and thus contributes to the interpretation of the survey results.

\subsection{Professionalism Assessment Tool Scores}

Pre- and post-term scores for each professionalism assessment tool (PAT) domain, shown in Table 1, were compared to determine whether student self-assessed professionalism improved over the semester. As the data was not normally distributed according to Shapiro-Wilks test, a Wilcoxon Signed-Rank test was used to identify instances of statistically significant increases in score $(\alpha<0.05)$. The statistical test revealed that all PAT domain scores increased significantly over the term, suggesting improved professionalism among Design III students based on the student's self-assessment. The effect size, however, showed that while statistically significant, the increase in scores was small. Lifelong Learning \& Adaptability had the largest effect, with a Cohen's $d$ of 0.29 . Overall, student total scores for professionalism increased by 6 , or 0.25 of a standard deviation.

Table 1: Comparison of mean professionalism domain scores from the beginning of Design III with the end of the course $(n=340)$. SD is standard deviation.

\begin{tabular}{|c|c|c|c|c|}
\hline Domain & $\begin{array}{l}\text { Max. } \\
\text { Score }\end{array}$ & $\begin{array}{c}\text { Pre- } \\
\text { Term } \\
\text { Mean } \\
\text { Score } \\
(\text { SD) } \\
\end{array}$ & $\begin{array}{c}\text { Post- } \\
\text { Term } \\
\text { Mean } \\
\text { Score } \\
\text { (SD) } \\
\end{array}$ & $\begin{array}{l}\text { Effect Size } \\
\text { (Cohen's } d \text { ) }\end{array}$ \\
\hline RRA & 25 & $\begin{array}{l}17.7 \\
(4.2)\end{array}$ & $\begin{array}{l}18.3 * \\
(4.1)\end{array}$ & 0.14 \\
\hline LLA & 35 & $\begin{array}{l}22.4 \\
(5.7)\end{array}$ & $\begin{array}{c}24.1^{*} \\
(5.3)\end{array}$ & 0.29 \\
\hline RwO & 45 & $\begin{array}{l}29.9 \\
(7.1)\end{array}$ & $\begin{array}{c}31.6^{*} \\
(6.7)\end{array}$ & 0.24 \\
\hline PIR & 40 & $\begin{array}{l}28.5 \\
(6.5)\end{array}$ & $\begin{array}{c}29.8^{*} \\
(6.2)\end{array}$ & 0.21 \\
\hline CPE & 20 & $\begin{array}{l}11.7 \\
(3.6)\end{array}$ & $\begin{array}{l}12.5^{*} \\
(3.6)\end{array}$ & 0.20 \\
\hline Overall & 165 & $\begin{array}{l}110.3 \\
(24.7)\end{array}$ & $\begin{array}{l}116.3 * \\
(23.3)\end{array}$ & 0.25 \\
\hline
\end{tabular}

* significantly greater than the pre-term mean score $(\alpha<0.05)$. Cohen's $d$ was calculated using the average standard deviation of the pre-term and post-term scores.
While the comparison results summarized in Table 1 are helpful for determining statistical significance and effect size, it is still challenging to understand what an increase of 6 or 0.25 of a standard deviation of a professional behaviour score means. It is made more challenging as the magnitude of the overall professionalism score is the sum of the five domain scores, each of which has a different number of items, and therefore, a different maximum potential score. As such, an average score was also calculated to depict the change in scores relative to the scoring system from Kelley et al. (2011): Knows, Know How, Shows, Shows How, and Teaches. Pre-term and postterm average scores for each domain and for overall professionalism are shown in Fig. 1.

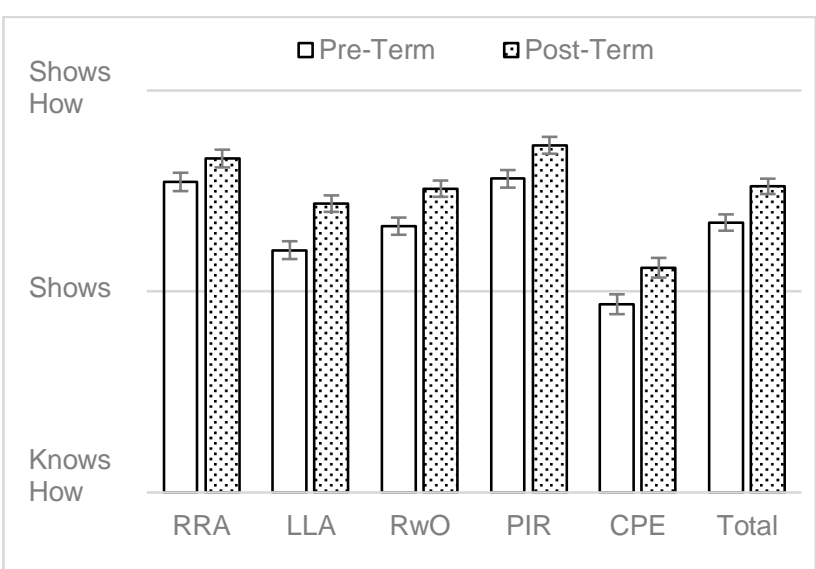

Fig. 1. Professionalism Assessment Tool domain mean scores pre- and post-term Design III, winter 2019. Error bars indicate the standard error of the sample $(n=340)$.

The domain abbreviations are RRA - Responsibility,

Reliability \& Accountability; LLA - Lifelong Learning \& Adaptability; RwO - Relationships with Others; PIR Upholding Principles of Integrity \& Respect; CPE Citizenship \& Professional Engagement.

Figure 1 shows that students self-assessed most of their domain scores between Shows and Shows How, suggesting they feel they can demonstrate most of the behaviours, and can demonstrate the procedural knowledge associated with the behaviour. None of the average scores, pre-term or post-term, approached the Teaches level, which suggest the students feel their skills are not akin to the instructors teaching the course. The PAT domain with the lowest mean score, for both the pre- and post-term surveys, was Citizenship \& Professional Engagement. While all mean post-term scores increased, the increases are small. As such, it is difficult to conclude that student professionalism improved by a meaningful amount during Design III.

\subsection{Student Reflections}

In the final reflections, students were asked to discuss their pre-term and post-term PAT scores, conduct peer evaluations of their team members, and reflect on their experience in Design III more broadly. When students 
discussed professionalism, whether regarding specific domains or their general professional behaviour, it was primarily in the context of skill improvement (40 of 53 reflections). The next most common type of professional behaviour comment was regarding a student's awareness of a professionalism domain. This was expected to be a common discussion point as professional behaviour was emphasized in the lectures and labs, and to the knowledge of the instructors had not been focused on in previous courses; however, there were only 10 reflections where students discussed their improved awareness of professionalism or one of the specific domains. This was followed by 6 reflections that indicated no change in a professionalism domain, and 2 reflections that discussed a decline in a professionalism domain.

When students wrote about how their professionalism improved as a result of their experience in Design III it was primarily due to their team, the project itself, or their own individual efforts. With respect to the influence of their team members on their improved professionalism, students commonly discussed their scores for the domain Reliability, Responsibility \& Accountability:

"Reliability, Responsibility, and accountability was something my team members noticed a change in...

I wanted to improve this specific domain because my team approached me and told me that this is a problem slowing down the team. I didn't want to disappoint my teammates...."

Comments that attributed elements inherent to the team's project as helping to improve their professionalism often discussed the individual's development of professional relationships with GTAs, instructors, industry contacts, and clients. For example:

"My ENGG*3100 design project presented a rare opportunity for students in this course as we were able to take on a real, existing problem that a business was facing ... Once my group was given the contact information of our potential Client... I volunteered to draft the first email... From that point on we decided that ... I would act as the sole contact point for communication with our Client. This responsibility had me communicating with the Client frequently... Our team also met on site with the Client twice throughout the project... This communication helped me develop my level of comfort with the art of professional communication when talking with a Client."

Alternatively, some students discussed how working with peers from different disciplines supported improvement in professional behaviour, and others individually put an effort into improving their professional behaviour.

There were only a few reflections that discussed the impact of the lectures, lab activities and assessments included in Design III to intentionally teach professionalism. With respect to awareness, students mentioned how brainstorming about professionalism in the lab, and discussing different aspects of professionalism, was beneficial:

"This course has taught me that a professional engineer is more than just technical knowledge, but also includes the behaviour and actions to back it up. For example, early labs in the course had us brainstorm what an engineer is or must have, and I had hardly thought of many of the characteristics my peers included. ... I also furthered my understanding of what it means to be an engineer as there is a whole professionalism and citizenship category that I had not fully thought about."

The self-assessment surveys were also identified as contributing to awareness of professionalism. One student discussed how the surveys helped them realize what areas of their professional behaviour they need to improve upon:

"Professional behavior is a crucial quality that every engineer must posses[s] in order to have a successful career. Therefore, reflecting on professional behavior during an individual's undergraduate period can help him or her improve specific characteristics. In ENGG*3100 completing the pre and post term surveys help the students come to a realization that certain qualities can be improved in various possible ways."

The remaining comments focused on the benefit of the lecture and lab activity that discussed how to have difficult conversations and provided students with an opportunity to practice giving oral feedback.

Based on the statistically significant, while small, differences in PAT scores, along with evidence from student reflections, it seems reasonable that student professionalism improved during Design III. A direct link to the intentional teaching strategies used, including lectures, lab activities, reflections and the self-assessment surveys, was only drawn by a few students. This means one can't conclude that the improvement in professionalism and professionalism awareness is necessarily due to the strategies implemented.

\subsection{Student Perceptions}

In the surveys administered over the semester, students were asked several questions regarding their perceptions of professionalism and Design III. One question from the post-term survey inquired whether students felt different professional skills could be taught. While the feeling was stronger that technical competencies can be taught, $94 \%$ of students at least somewhat agreed that professional behaviour can be taught. In fact, students were more confident that professional behaviour can be taught than teamwork and lifelong learning. This surprised the research team, but it was encouraging that nearly all students saw the value in teaching professionalism in the course.

In the final reflections students were asked to comment on whether they felt the scores they received from the PAT were reflective of their capabilities. Their perspective 
provided insight into the effectiveness of the tool for selfevaluation. The results are shown in Fig. 2. The majority of reflections indicated the PAT scores were reflective or mostly reflective of their experience.

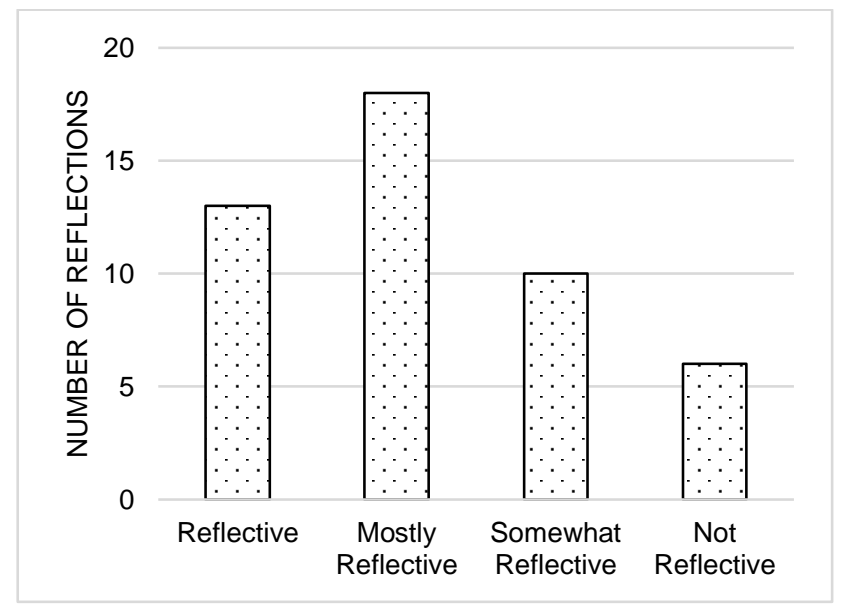

Fig. 2. How reflective the Professionalism Assessment Tool is of the students' experience $(n=53)$

Of the students that found the scores not reflective or somewhat reflective, many commented on how their awareness of professionalism increased, and as such the scores were not reflective of their professionalism initially. For example, one student stated the following:

"Across all domains, my scores decreased from pre term to post term...when I did the pre term survey, I did not have an accurate understanding of the topics or my own ranking in them."

Some students felt like their mood and feelings while taking the post-term survey compared to the pre-term survey may have influenced the accuracy of their scores. For example:

"My original score was 0.76 and my final score was 0.60 . I feel as if my scores show that I was more honest in my post term survey and overstated how I felt about myself in the pre term evaluation. My current level of anxiety also has made my view of myself very skewed and so I feel this has dropped my score lower than it should be."

These factors are important to consider regarding the effectiveness of self-assessment tools in estimating professional behaviour. While the tool is validated, improved understanding of professionalism after taking the first survey, suggests a threat of maturation and/or testing to the validity of the experimental results.

Students also discussed aspects they disliked about the tool. For example, the PAT scale was generated for doctoral pharmacy students, and a student argued that the tool is not appropriate for use in a third-year engineering design course as the maturity of the students differs. Another student commented on the scale used in Kelley et al.'s (2011) PAT:
"Overall I find these scores a fair assessment of my position, but I will say I find them difficult to connect with only because of how the domains were assessed. The "Know", "Know How", "Show", "Show How" and "Teach" terms of the survey were unfamiliar, and in my opinion, hard to relate to. Still, I think reflecting in these areas is valuable."

Other students also anecdotally shared their frustration with this alternative scale saying it was difficult to understand what the difference between the different levels were. The familiarity of a traditional Strongly Disagree to Strongly Agree Likert scale may have been better received. Generally, however, most students seemed content with the self-assessment tools applied and found the scores were reflective of their experience.

\section{CONCLUSIONS}

Kelley et al.'s (2011) Professionalism Assessment Tool was successfully employed in a multidisciplinary senior engineering design course. The tool was generally well received with most student reflections indicating their PAT scores were reflective or mostly reflective of their experience. Some of the concerns students had with the tool included an unfamiliar scale, and whether it is applicable to undergraduate engineering students given the demographic it was designed for. Further, some students identified a limitation with how the tool was delivered because the pre-term survey was before the professionalism workshop, and as such their understanding of what professional behaviour is and consequently their ability to self-assess at that time was inadequate.

Despite potentially inflated pre-term PAT scores, the results of the quasi-experiment suggest that student professional behaviour did improve over the semester. The difference in mean scores was small, but many of the student reflections support an improvement in professional behaviour in the course; although, these improvements were not necessarily attributed to the intentional instruction employed (e.g. lectures, professionalism workshop). Some students, did however, discuss an improved awareness of professionalism, which was an unexpected, but important outcome of introducing the PAT-based course material. It is possible this increased awareness may have reinforced student ownership of their professional behaviour, thus supporting self-motivated behavioural changes.

A limitation of this paper is that it presents only student self-assessments and perceptions. While this form of data is important, self-assessments can result in biased evaluations. Student professionalism may be better estimated by triangulating assessments on an individual, from different perspectives. In addition to the selfassessments in Design III, the researchers collected peer and instructor/GTA assessments on student professionalism. Peers assessed their team members on each of the PAT domains, while instructors/GTAs evaluated each student on professional behaviour broadly. 
The 33 PAT items were not answered directly in these assessments, but assessors were instructed to review the PAT items for guidance. While triangulating this data with the self-assessment PAT scores also presents limitations, it suggests progress towards effective assessment of student professional behaviour in large courses like Design III.

Research on teaching and assessing professional behaviour using the PAT in Design III continued in winter 2020, with some changes based on the results from 2019. For example, the professionalism workshop was done before students completed the pre-term survey and it became an opportunity to train students on the unfamiliar scale. Further, the workshop made students aware of what professionalism encompasses before the pre-term survey with the intent of minimizing pre-term score inflation. It also supported continued use of the PAT as a teaching tool, as well as assessment tool. Recognizing the broader value of the PAT as a teaching tool was an important outcome of this study. Future research will investigate the impact of increasing student awareness of professionalism using the PAT on fostering professional behaviour.

\section{Acknowledgements}

The authors would like to thank the winter 2019 Design III teaching team. The instructors and GTAs were very supportive of changes in the course to teach and assess behavioural professionalism. Further, this work would not have been possible without the support of the University of Guelph's School of Engineering and the students in the winter 2019 offering of Design III.

\section{References}

[1] Canadian Engineering Accreditation Board, A Guide to Outcomes-based Criteria. Draft V 1.25, Mar. 2015.

[2] PEO, Become a Professional Engineer. Professional Engineers Ontario.

Available as of February 9, 2020, from https://www.peo.on.ca/licence-applications/becomeprofessional-engineer

[3] Engineers Canada Board, Public Guideline on Good Character. National Guideline, Mar. 2013.

[4] Engineers Canada Board, Concepts of Professionalism for Engineers. Engineers Canada, National Model Guide, Apr. 2010.

[5] J. Evetts, "Sociological analysis of professionalism: Past, present and future," Comp. Sociol., vol. 10, no. 1, pp. 1-37, 2011, doi: 10.1163/156913310X522633.

[6] J. Evetts, "Professionalism: Value and ideology," Curr. Sociol., vol. 61, no. 5-6, pp. 778-796, Sep. 2013, doi: $10.1177 / 0011392113479316$.

[7] S. Stawiski, A. Germuth, P. Yarborough, V. Alford, and L. Parrish, "Infusing twenty-first-century skills into engineering education," J. Bus. Psychol., vol. 32, no. 3, pp. 335-346, Jun. 2017, doi: 10.1007/s10869016-9477-2.

[8] S. D. Sheppard, K. Macatangay, A. Colby, W. M. Sullivan, and L. S. Shulman, Educating Engineers: Designing for the Future of the Field. San Francisco, CA: Jossey-Bass, 2009 (1 st ed.), 242 pp.

[9] A. Woolfolk, P. H. Winne, and N. E. Perry, Educational Psychology. Don Mills, ON: Pearson Canada Inc., 2016 (6th ed.), 656 pp.

[10] J. Goldie, "Assessment of professionalism: A consolidation of current thinking," Med. Teach., vol 35, no. 2, pp. e952-e956, Feb. 2013, doi: $10.3109 / 0142159$ X.2012.714888.

[11] C. R. Rogers, On Becoming a Person: A Therapist's View of Psychotherapy. Boston, MA: Houghton Mifflin Company, 1961, 420 pp.

[12] C. Paterson and J. Chapman, "Enhancing skills of critical reflection to evidence learning in professional practice," Phys. Ther. Sport, vol. 14, no. 3, pp. 133138, Aug. 2013, doi: 10.1016/j.ptsp.2013.03.004.

[13] K. Mann, J. Gordon, and A. MacLeod, "Reflection and reflective practice in health professions education: A systematic review," Adv. Health Sci. Educ., vol. 14, no. 4, pp. 595-621, Oct. 2009, doi: 10.1007/s10459-0079090-2.

[14] K. A. Kelley, L. D. Stanke, S. M. Rabi, S. E. Kuba, and K. K. Janke, "Cross-validation of an instrument for measuring professionalism behaviors," Am. J. Pharm. Educ., vol. 75, no. 9, p. 179, Nov. 2011, doi: 10.5688/ajpe759179.

[15] D. P. Hammer, H. L. Mason, R. K. Chalmers, N. G. Popovich, and M. T. Rupp, "Development and testing of an instrument to assess behavioral professionalism of Pharmacy Students," Am. J. Pharm. Educ., vol. 64, p. $12,2000$.

[16] M. A. Chisholm, H. Cobb, L. Duke, C. McDuffie, and W. K. Kennedy, "Development of an instrument to measure professionalism," Am. J. Pharm. Educ., vol 70, no. 4, p. 85, Sep. 2006, doi: 10.5688/aj700485.

[17] D. Lakens, "Calculating and reporting effect sizes to facilitate cumulative science: a practical primer for ttests and ANOVAs," Front. Psychol., vol. 4, 2013, doi: 10.3389/fpsyg.2013.00863.

[18] H.-F. Hsieh and S. E. Shannon, "Three approaches to qualitative content analysis," Qual. Health Res., vol. 15, no. 9, pp. 1277-1288, Nov. 2005, doi: $10.1177 / 1049732305276687$.

[19] G. Guest, A. Bunce, and L. Johnson, "How many interviews are enough?: An experiment with data saturation and variability," Field Methods, vol. 18, no. 1, pp. 59-82, Feb. 2006, doi: $10.1177 / 1525822 \mathrm{X} 05279903$. 